\title{
MODERNIDAD Y MORALIDAD DE LA MUNDIALIZACION*
}

\author{
Manuel María Zorrilla Ruiz \\ Catedrático de la Universidad de Deusto \\ Profesor Visitante de la Universidad «Montesquieu» de Burdeos (Francia), \\ de la Universidad de £odz (Polonia) y del Instituto Pernambucano \\ de Derecho del Trabajo de Recife (Brasil)
}

\section{Significado de la ideología de lo justo}

La ideología de lo justo supera el pluralismo -inútil de presentede las variantes caducas o las corrientes ideológicas desvalorizadas. Denuncia, por indignas de crédito, las incursiones de un pensamiento débil y obediente a premisas defectuosas. He aquí algunas de ellas. Deserción y abandono de los focos auténticos de especulación y de consejo. Suplantación de esos centros por actividades de pensamiento que carecen de significación elemental. Olvido - más por desconocimiento técnico que por desinterés académico- de los desafíos de la economía. Elección de valores secundarios que, apoyados en un discurso exento de poder de convicción, facilita las adhesiones incondicionales de cuantos, como menos inteligentes, muestran su escasa capacidad comprensiva. Exaltación de personalidades marcadas por actitudes de vulgaridad o megalomanía que ocultan otras insuficiencias. Magnificación de los sucesos en que dichos agentes intervienen y apología de los cambios de rumbo que protagonizan. Falso convencimiento de que, pese a la fragilidad de los factores del producto intelectual y moral de una época, los instrumentos de lucha - aun contando con la flaqueza del bagaje que se tiene a mano- se conservan y son de manipulación imprescindible.

La ideología de lo justo debe, a toda costa, deshacer esa contrafigura. Es más, tiene la obligación de ignorarla irrevocablemente. Ha de sobrepasar, a fin de merecer confianza, las posturas del pensamiento

* Texto de la comunicación que, para el Area 17 (Humanismo en clave social), se presentó al Congreso Internacional: Humanismo para el siglo XXI, Facultad e Instituto de Ciencias de la Educación, Universidad de Deusto, Bilbao, 7 de marzo de 2003. 
único que adolecen de los siguientes vicios. Elusión del elemento intelectualista de formación de la opinión pública y preferencia por el adoctrinamiento procedente de los medios de comunicación audiovisuales. Andanza a la deriva, causada por el fracaso de las economías de estirpe socialista, por la explotación de esta circunstancia en las recientes ediciones del neoliberalismo salvaje, y por la ineptitud para conseguir soluciones que liquiden su interinidad. Recepción de valores dirigidos al halago de la sociedad y dependientes de ciertas opciones - modernizantes e insensatas - de sus individuos y grupos. Divergencia entre el concepto - formalmente democrático y gradualmente abandonado - de la Moral política, y la promoción febril — que se pone de moda y vigoriza- de la inerrancia e infabilidad del jefe o conductor. Sustitución del estilo discreto — que debe animar las acciones políticas, sociales y económicas - por un sistema, si así cabe llamarle, de abominación del adversario, que, lejos de aprovechar su predisposición cooperativa, resalta su inesciencia — pasada, presente y futura - para proyectos de esa magnitud. Preterición —escandalosa, muchas veces - de las situaciones de interés general que exigen atención, y anteposición, no menos descarada, del espectáculo que ofrecen las luchas dirigidas a la conquista y acaparamiento del poder.

La ideología de lo justo disuelve los reductos intelectuales del pensamiento débil y purga las miserias del pensamiento único. Descansa en unas cuantas consideraciones. Constitución — con lo que de disuasorio tienen las objeciones de metodología - de una opinión pública ilustrada y activa, capaz de diagnosticar los males de la sociedad pluralista y de movilizarse para eliminarlos, desoyendo el recetario dogmático de los medios de comunicación e información. Solución racional de los problemas económicos, sobre todo de las deformaciones y cambios que la mundialización ha traído. Reconocimiento y efectividad del valor de la justicia, como una síntesis de igualdad material, que va en busca de la libertad verdadera, y de libertad que fomenta el desarrollo íntegro de la personalidad humana. Todo lo contrario de una libertad enturbiada, desde sus orígenes, por el mensaje de la seudoigualdad que prostituye sus adquisiciones más preciadas. Devolución — no menos efectiva- al pueblo del poder político, mediante la concienciación y puesta al día de sus responsabilidades. Destierro de los adoctrinamientos, halagos y conminaciones con que los poderes democráticos de hoy día gustan de obsequiar a una sociedad hipotecada por muchas formas de sumisión y servidumbre. Transparencia de los resultados habidos por los responsables sociales y prohibición de ocultar los fracasos — quizás remediables con otros auxilios - o engrandecer aquellos éxitos que lo son menos o no tienen condición de tales. Conversión de la vida pública en el espa- 
cio de intercomunicación que su plenitud requiere, y no en un reducto que - acusando la ferocidad de la enemistad política - invita a la insinceridad y al hermetismo. Como si, regresándose a una vieja censura, la mentira -instrumento de manejo generalizado y ventajoso- no pasase de ser un discreto pecado venial que circula en el mercado de la vida pública.

\section{Emergencia de la mundialización}

Los designios y perversiones de la mundialización — que, pese al esfuerzo hagiográfico de sus defensores, son bastantes- se oponen, de raíz, al prevalecimiento de un juego de valores que sitúa la justicia en la cima de su concurrencia. Las imágenes liberalizadoras de la mundialización - activadas por el decisionismo económico que oculta sus fuentes de generación- constituyen, si se revisa el inventario de sus logros, el impedimento más formidable de cuantos interceptan los caminos que llevan al triunfo de la ideología de lo justo.

La cosmovisión mundalizadora propende a suprimir —natural o artificialmente - las restricciones y/o barreras que de antiguo frenaron unas vicisitudes - políticas, sociales y económicas - cuyos rasgos diferenciales se entremezclan a medida que la Historia aguarda, a la vuelta de la esquina, la respuesta a sus interrogantes más temibles. El marco territorial del ejercicio de la soberanía del Estado supuso - mientras conservó su carácter de categoría dogmáticamente ineludible- el óptimo ámbito de esas relaciones y el límite de su equilibrado desarro1lo. No obstante, se fue desdibujando ante la tendencia general -fomentada por la realidad del crecimiento saludable y por ciertas perversidades de la intercomunicación - a que los acaecimientos vitales de la familia humana se escenificasen en los espacios sin fronteras que inhibían los prejuicios domésticos de antaño y apoyaban la movilidad de sus protagonistas. El ritmo de esta evolución se señalaba por la velocidad de crucero, que aumentaba la cifra de sus experimentos, y por la vehemencia de sus inquietudes de conquista.

La mundialización de hoy día constituye un concepto jurídico, social y económico, indeterminado - amén de acampar en otras esferas que se la disputan- y expuesto a la aventura en que su pléyade de codefinidores se sumerge. Mundializador es cada momento del estado de cosas - plural e ineludible para la acción y el pensamiento de cuantos advierten sus manifestaciones- en que, al margen de apariencias confusas y difusas, se presienten la aparición y el progreso de esas inclinaciones expansivas. A reserva, todo ello, de una evolución despro- 
vista de reglas — que faciliten las predicciones más elementales- e inundada de acontecimientos que desencadenan agresiones y crisis torrenciales. La mundialización - deontológicamente contradicha por tales experiencias - no es la clave ideal para rehacer un universo que, llamado a difundir el bien, quiere enmendar los más inhumanos de sus yerros.

La mundialización se instala en el dominio — resbaladizo y variopinto- de los excesos ambiguos o malevolentes, las imprevisiones y los aventurismos insensatos. Se da la paradoja de que un mundo achicado - cuyas peripecias más modestas son objeto del conocimiento general, que no siempre criba la verdad histórica de las versiones recibidas, y de las censuras especializadas - encierra ocultismos que pertenecen al misterio de su esencia y le convierten en un enigma indescifrable. Las situaciones anómalas - genéricas o específicas- que la mundialización desencadena, desconciertan a los pobladores de aquellos espacios, aunque, en vez de arrastrarles al pesimismo de la desmemoria, desafíen su curiosidad. Lo hacen con el asombro que experimentaron los primeros cultivadores de la filosofía, pero también les acompaña un ímpetu de reto que alivia la melancolía consiguiente a los fracasos del acercamiento a la verdad apetecida. El hecho mundializador conmueve las conciencias individuales y colectivas para que - visto su impacto en el desarreglo de las vidas injustamente organizadas- se intente, más allá de un copioso anecdotario, agotar el análisis de los cambios que subyacen a sus realizaciones.

\section{Pasado edificante de la mundialización}

La mundialización imprimió carácter a la era de los descubrimientos que, como cuestiones centrales, planteaba las que guardaban parentesco con la libertad de tránsito entre continentes y el ejercicio de una incipiente economía de mercado que dependía de estas novedades. La primera conectaba con pretensiones colonizadoras en que lo supuestamente espiritual ocupaba el lugar de otros afanes y no daba entrada a las insinuaciones de reformas sociales. La segunda comulgaba con la filosofía del éxito, asociada por la Moral del reformismo protestante a los triunfos que remuneraban la laboriosidad austera de quienes - antes de lucrar las excelencias sobrenaturales de otro mundo- disfrutaban de algunos beneficios del presente. De ahí, la variedad de ambiciones, interrogantes y utopías que nacieron de semejantes actitudes.

Todo un acervo de expectativas y alicientes se concentraba en torno a la primera muestra de conciencia pluricultural. Sus problemas se 
abordaron de modo incompleto, con el maximalismo de los derechos de conquista y la oscurividencia de momentos históricamente inadecuados para el serio ejercicio de la crítica y la sana práctica de la disidencia. Aún así, el depósito de esas contribuciones no se ceñía a un acto de presencia de tan impresionantes novedades, pues, por modestamente que los signos de los tiempos elevasen el tono de censura, obligaban a una reflexión que los reclamos de la razón y la mala conciencia, en caso de desoírse su llamada, hacían prevalecer a fin de cuentas. Algunas cuestiones emanaban de las dudas anejas a la recepción de los nuevos derechos naturales de la comunicación, pues costaba defender que los inmovilismos de las actitudes personales y la tosquedad de las instituciones de antaño primaban sobre una movilidad justificada por las poderosas razones que se alegaban en su pro. Otras mostraban cómo la soberanía unitaria del Estado absoluto -impermeable e incomunicado hasta entonces - dejaba de ser la verdad oficial y se sustituía por el concepto de interdependencia, augurando la suerte de las organizaciones internacionales que, andando el tiempo, ocuparían las parcelas de una soberanía mitigada por esa innovación. De ahí, la dificultad de erigir un Derecho de Gentes que predecía los escollos del futuro Derecho Internacional Público, debido al disenso sobre el contenido material de sus principios y preceptos, a las insuficiencias que, para perfeccionar una justicia suficiente, encerraba su coercibilidad defectuosa, al predominio de lo transaccional sobre lo normativo, y a la injerencia de consideraciones metajurídicas que le acercaban teóricamente a la Moral y le alejaban prácticamente del Derecho.

El mundo se achica porque el problema de la libertad de los mares cuenta, de una parte, con elementos racionalizadores que desvanecen los reparos opuestos a sus soluciones, pero no ignora las intransigencias y recelos que despierta el designio de comprometerse con el establecimiento y arraigo de la paz. Este empequeñecimiento se enfrenta a las condiciones políticas de una soberanía absoluta que la teología jurídica de su tiempo denuncia con una energía que no suaviza la aplicación de sus premisas. Abundan las tentativas doctrinales de explicar - con apasionamiento didáctico - los atractivos que un mundo abierto, como el que entonces se diseña, oponen a la enemiga de cuantos le ignoran y hostilizan. Se preconizan las ventajas que, en un porvenir alentador, ofrecerá - a cuantos saben creer en la esperanza- la interdependencia de las comunidades políticas. Integradas, conforme a la naturaleza de las cosas, en otras superiores que rejuvenecen sus atribuciones, ordenan las relaciones que les corresponden, moderan lo áspero de sus enfrentamientos y adiestran en el arte de sustituir el recurso a la fuerza por la terapia pacificadora de la inteligencia bondadosa. No son de me- 
nor enjundia los problemas a que, en función de las variables apuntadas, darán lugar las peripecias del comercio internacional.

\section{Efecto convincente de la mundialización}

La mundialización definió las posturas que los reformadores sociales europeos de los siglos XVI y XVII adoptaron, al proclamar que la doctrina idealista del orden natural era inservible, porque anteponía la simulación de las necesidades a su veracidad histórica, y superable, pues los estados de conciencia de la época presentían la urgencia de un sustitutivo fiable y eficaz. De ahí, la opción por un yusnaturalismo realista, moderno y provechoso. La primitiva orientación reducía el significado de lo justo a una síntesis de la asistencia sobrenatural, sin cuyo apoyo dicho conocimiento era imposible, y del auxilio de la razón humana, resuelta a su descubrimiento. La posición realista pasó a considerar, como móvil y eje de todo su discurso, la sensibilidad y el tino exigibles para seleccionar las necesidades inéditas que aparecían en los horizontes de la razón práctica.

La mundialización conectó, acto seguido, con la idea de que los principios jurídicos emanados de la filosofía política del Estado demoliberal, gozaban de una fisionomía inalterable. Provenían de la invención - sinónimo del hallazgo de algo preexistente- de unos derechos que no pertenecían a la persona humana por la condición de creyente falible, que el idealismo yusnaturalista defendía, sino por el valor $y$ cualidad de ser creado, que se reconocía en la reflexión de las aspiraciones sociales. La mundialización no era el acceso a un universo de ocurrencias -más o menos imaginativas - y sí el recurso al utillaje del entendimiento que - atreviéndose, una vez más, a pensar- ocupaba, en su cielo de libre pensamiento, lo que, tiempo atrás, se había descubierto en los grandes espacios geográficos.

La mundialización tradujo su convencimiento en la acogida — primero intelectualmente fatigosa y luego repleta de evidencias- de los derechos que acompañaban a los seres humanos desde su advenimiento a este mundo, y que, al acrecentarse con el progreso personal, aumentaban su espectro de oportunidades provechosas. Derechos que se estimaban intangibles, porque, al originarse en el hecho de cada existencia individual, la condición de naturales o cuasinaturales les defendía de las agresiones arbitrarias con que el poder soberano intentaba modificar su sustancia o desfigurar - sustituyendo lo natural por lo graciable o complaciente- los títulos de su pertenencia al depósito de bienes jurídicos que los alojaba. Derechos precedentes a los arbitrios o prejuicios del 
Derecho humano, que, lejos de ejercitar el poder de crearlos, tenía la obligación moral y política de referir a ellos- solícita y fielmentelas soluciones de interés general que los legisladores preferían. Su existencia y consistencia condicionaban unas iniciativas que, respaldadas por su fuerza informadora, hacían resonar en su mensaje - no siempre de comprensión perfecta, pero certeramente cursado a sus destinatarios- el eco de los signos de los tiempos, para resituar esos derechos subjetivos, una vez ordenados, en el sector del Derecho objetivo que les correspondía.

La mundialización designó el esfuerzo tecnicojurídico que, ante la comprensión de esos principios, aspiró a realizarlos en el espacio cultural que les estaba reservado. Mundializarlos era iniciar y concluir, con algún éxito, las operaciones de racionalización que, actuando sobre materiales envejecidos y dispersos, producirían dos efectos. Uno, el de hacer de ellos elementos aprovechables para la regeneración justa —aunque esta rotulación se obviase- y la juridificación de la vida social. Otro, el de aplicar —en el más exacto sentido escolástico- a esa materia, la forma de unos postulados que la recta razón no asumía de modo confuso y fragmentario, sino que adquiría, sin ayudas sobrenaturales, con su destreza de dilucidación. Ello hizo posible que las máximas y/o las proposiciones que condensaban su excelencia, se atuvieran a criterios científicos y sistemáticos que - socavados, con el tiempo, por los sentimientos nacionales - perdieron el, más que discreto, encanto de la universalidad que poseían. Las tentaciones centrípetas primaron, a la postre, sobre la generosidad centrífuga de la codificación y empobrecieron el entusiasmo de sus defensores. Las invocaciones al espíritu del pueblo - que determinaron entendimientos muy varios - no detuvieron la expansión de un hecho codificador que, coasentido por todos los países civilizados, soportó el conflicto con los nacionalismos afectos a lo singular de sus fisionomías. Algo así como si esa especie de mundialización - apenas impuesta y victoriosa- abriese la cronología del desgaste de un Derecho común sabia y costosamente reconstituido.

La mundialización ha caracterizado a la reacción —-dramáticamente escarmentada - que exhibe el espectáculo de las confrontaciones entre Estados y bloques, cuya afición común parece ser, pese a lo ingenuo de las apariencias, la negativa a erigir una paz justa y la multiplicación, directa o velada, de las dificultades para salir, sin paliativos, a su encuentro. Mundializar la existencia pacífica es contraer el sincero propósito de crear organismos cuya eficacia elimine o disminuya los antagonismos nacionales o afines. Con otros frentes que la modernidad ha ofrecido a las expectativas mundializadoras, 
coexiste una parcela cuya fertilidad está servida por los protagonistas más sombríos y en la que nunca faltan los encargados de revisar y poner al día el programa sangriento de las opciones bélicas. Hasta la Iglesia Católica recuerda que acaso la paciencia divina -inagotable, hasta el día de hoy, según el dictamen de la Teología- se está desdiciendo de esa infinitud y, cargándose de razón, condena la maldad y tozudez con que algunos pobladores de la humanidad invitan a compartir tales aberraciones.

\section{Mundialización promotora de los valores sociales}

La mundialización plasmó la efectividad del esfuerzo — alentado por la influencia sindical y la insistencia con que la solidaridad supranacional evocaba el renunciado proyecto revolucionario- de las instancias internacionales que tecnificaron, poniéndolos en negro sobre blanco, los requerimientos de un Derecho de Gentes que, a la usanza del antiguo Derecho común, constituían el depósito cuasiyusnaturalista del naciente Derecho Social y reclamaban su incorporación a los ordenamientos jurídicos de la modernidad. Así surge la mundialización de dos velocidades. La parte indiscutida de sus soluciones profesaba - para llevarlas a los países industrializados con economía de mercado- un cuerpo de doctrina intangible que, atento a los signos de los tiempos y fiel a la naturaleza de las cosas, proclamaba principios cuyo enunciado escrupuloso no procedía del prejuicio estético de sus proposiciones, sino de las verdades evidentes que facilitaban. Eran el eco de la fuerza moral que asistía a la voz y el aliento de los efectivos sindicales arraigados en los reductos de sus acciones de solidaridad y de denuncia. Pertenecían a experiencias vividas con delectación semejante al optimismo que, en el siglo de las luces, había elogiado la victoria del atrevimiento pensante y que después se había sumado a las alabanzas del hecho codificador. El otro grupo de soluciones -inspiradas en postulados relativos o circunstanciales del Derecho de Gentes- preservaba, con alguna templanza, su alcance mundializador, aportando las sugerencias de un Derecho de contenido variable, pero no inmaduro ni precipitadamente concebido, dependiente de su ajuste a las coyunturas históricas o de su implantación en los ámbitos geográficos que las delimitaban. Un Derecho recomendable y digno de análisis, con vistas a su posible recepción.

La diferencia muestra cómo las modernas sociedades se han visto compelidas por el reto mundializador de soluciones uniculturales y cuasiaxiomáticas que - para disipar los reparos de mora o antiyusna- 
turalismo social por omisión- tienen que pasar, cuanto antes, a remozar el Derecho Positivo. El asentimiento a las soluciones condicionadas o de segunda velocidad, depende de la diligencia que - optando en uno de varios sentidos - prestan los poderes públicos que conocen de dichas propuestas. Algunas de ellas se condicen con las disponibilidades sociales y jurídicas, pudiendo perfeccionarse desde ya, o, al contrario, hay que esperar a las realidades sociales de un futuro más despejado y próspero. Cabe defender su aceptación con salvedades o enmiendas que incluyen soluciones intermedias, subordinadas a las vicisitudes históricas y las sensibilidades de cada comunidad, que puede adoptarlas con reservas o, si lo juzga más prudente aplazar su decisión.

Desde la línea de salida de la mundialización, se atisbaban también los objetivos que guiaron los primeros pasos - luego desandados o perdidos - hacia la tierra prometida de la Europa Social, aún hoy inacabada y pendiente. Se pretendía conjurar los problemas de crisis económica que planteaba la consunción de los yacimientos extractivos de sectores industriales básicos y salvaguardar la ocupación profesional deteriorada por el colapso de las explotaciones. La inclinación mundializadora dependía más de una preocupación social - la de rescatar el empleo devastado en un amplio mercado de trabajoque del propósito de proteger los valores ligados a la libertad de empresa que dominaba la economía del sistema. Entraba en juego un cúmulo de cargas que - yuxtapuestas a esa libertad - movilizaban las funciones sociales -inseparables de las renovaciones del Estado social y democrático de Derecho- que incumbían a los propietarios de los instrumentos y medios de producción. Esa mundialización ya intuía - a una escala en que se dieron cita la certidumbre del modelo social preferido y los riesgos de la experiencia de laboratoriocómo la libre circulación de mano de obra se institucionalizaría en un espacio accesible a las demandas de ocupación absorbidas por ofertas concretas - todavía no indistintas y genéricas- que se cursaban a los trabajadores en el novísimo escenario del mercado europeo. La mundialización exaltaba la libertad de establecimiento y su Política Social menguaba la onerosidad de los gravámenes que sus titulares soportaban. Las reconversiones y reestructuraciones industriales - a que se sujetaba el ejercicio de esa libertad-consistían en la mudanza de las unidades productivas - desplazadas a otros lugares geográficos - o en la adhesión a complejos industriales cuyas condiciones de amplitud saneaban la deteriorada dimensión de las empresas que, así transfiguradas, retornaban a un mercado en que se les otorgaba cabida. 
A este capítulo mundializador se sumaron, como complementos obligados, las experiencias de readaptación profesional que - para restaurar la correlación entre la fuerza y las ofertas de trabajo, y flexibilizar la continuidad de la producción- concurrían en procesos de evolución variable. Los unos mantenían la identidad de los bienes y servicios dados al mercado, y sobrevivían gracias a las ayudas tecnológicas que purgaban sus obsolescencias. Los había que cedían su lugar a explotaciones distintas de las afectadas por la crisis y centraban su esfuerzo de competición en zonas enriquecidas con la apertura de mercados que incluían actividades preexistentes o estrenaban otras de nueva factura.

Esta pauta mundializadora animó la idea de crear un espacio europeo complejo y extenso, cuya meta era la unificación política que, de consumarse alguna vez, pondrá en serios aprietos la redefinición del concepto de soberanía estatal, a cuyos reparos de presente se añadirán objeciones de peso. La implementación - a largo plazo y, por ello, polémica y tediosa- de ese estado de cosas, requiere ordenar los mecanismos y asegurar el buen fin de la integración económica y monetaria. Pese a las protestas testimoniales y las apariencias de progreso, perduran las desconfianzas - fruto de una aleccionadora experienciafrente a la demora en perfeccionar una Política Social a la que la voluntad europea de hoy día no se adhiere con mucho entusiasmo. No siente ansiosamente la necesidad de llevarla al grueso de su programa mundializador. La idea minimalista de la coordinación de las políticas sociales nacionales — basada en la premisa, disuasoria y discutible, de que lo mejor es enemigo de lo bueno-y la calculada modestia de ulteriores retoques, no libra a la Política Social — que, en este caso, dista de ser llamada por su nombre- del estigma de pariente pobre en la familia de las políticas comunitarias. La elevación reciente -en textos europeos cuya eficacia preceptiva directa supera el platonismo de proclamaciones anteriores- de los derechos sociales a la categoría de derechos fundamentales, lejos de avivar la creatividad de las instituciones comunitarias y los poderes públicos de los Estados miembros, acentúa su desgana en servir a tan importante reconocimiento. El indisimulado economicismo de las instituciones comunitarias acredita su apuesta por los valores de este signo y el magro propósito de adjudicar a los derechos sociales la condición jurídica que les incumbe. La opinión pública — que no se deja adormecer por la propaganda de la literatura europeísta- es consciente, hace tiempo, de ese desinterés. La mundialización - algo así como escapando de puntillas- ha rechazado el reto y se ha batido en retirada, porque las predilecciones de sus artífices siguen siendo distintas y distantes de las que exige un tratamiento a fondo de las cuestiones de la Política Social. 


\section{Mundialización disolvente de la Política Social}

La arrogancia de la mundialización — que se fortifica y gana terreno- se debe al fracaso del plan que pudo haber detenido su avalancha y repuesto las cosas al estado en que la Política Social se resignó a los criterios — cuerdos e inevitables - de la flexibilidad. La situación mundializadora de crisis económica fue algo más que un entorpecimiento reversible, cuya eficacia terapéutica dependía de renuncias que - templando provisionalmente los antagonismos del conflicto industrial - aportaban elementos de morigeración de sus fricciones y reclamaban actitudes cooperativas para reconquistar el paraíso perdido de la prosperidad y la plena ocupación. Si los empleadores y los sindicatos coaceptaron un contexto de diálogo y entendimiento, lo hicieron para remediar un estado de cosas que amenazaba los intereses de unos y otros. La mundialización — alentada por las amnesias de la libertad económica que se desentendía de sus funciones sociales- derivó en una malévola coartada. La flexibilidad y la desregulación - presupuesto y efecto respectivamente de una tempestiva mundialización de la Política Social - sufrieron el asalto — brutal e irresistible - del neoliberalismo salvaje. Los agentes perversos de la mundialización agravaron las rebajas de aquellos sacrificios y, pareciéndoles poco las agresiones contra su cuerpo y alma, se confabularon para liquidar las - ya depredadas- posesiones del Derecho Social.

El examen de la mundialización revela cómo - tras esta comprobación desoladora- proliferaron las oportunidades y ocurrencias que algunos poderes de Derecho y los —más codiciosos- poderes económicos aprovecharon para una detestable sustracción. Los portadores de los intereses económicos se alejaron de sus interlocutores naturales - que, desde su renuncia a la revolución, eran los sindicatos- y les privaron de la movilidad necesaria para ejercer sus funciones con dignidad cabal. Su congelación les abocó a situaciones de inactividad e insuficiencia. La distancia física — que así se consumaba- interpuso barreras insalvables entre los sujetos del conflicto industrial e invalidó los mínimos que avalaban la continuidad de su tratamiento y sus contactos. La gestión de sus incidencias perdió igualmente la razón de ser, porque, al desplomarse la confrontación, la parte más débil —empobrecida e indefensa - se vio atrapada en un campo de juego abandonado por los adversarios, que se dieron a la fuga, e inservible para cualquier empresa de relevancia sindical.

Aunque el avance de los sucesos mundializadores es notorio, hay que escrutar - con delicadeza y lucidez- los procesos de aglutinación y sutura de los bloques que forman su totalidad. No puede desistirse, 
pese a la dificultad de la faena, de indagar la reunión sistemática de sus resultados finales. Las variables de lugar y de tiempo son tan retadoras como ingentes, porque, sin ignorar lo expansivo de sus realidades, quedan extremos pendientes de aclarar. ¿Cuáles son los rasgos distintivos del ciclo al cabo del cual la mundialización se instala - por derecho de conquista - y alcanza los máximos de su fuerza conminatoria y destructiva? ¿Cómo es el inventario de las consecuencias, más lesivas que beneficiosas, que derivan de unos adelantos - tecnológicos y económicos-cuyas ventajas se falsifican o exageran?

La mundialización es la acción y el efecto de la retirada de los empleadores que desertan de los escenarios del conflicto industrial en que radicaba el antagonismo de las relaciones colectivas y se resolvían las controversias - jurídicas o económicas - que afectaban a la normalidad de sus tensiones. La libertad de establecimiento no se ejercita hoy - como enseñaba la deontología pactada del período de la crisis económica- en dependencia de sus funciones sociales. Pretende que, sin trabas, la ejecución de los procesos productivos se traslade a comunidades lejanas y ajenas a unas oportunidades sindicales — de oposición y de crítica- que disienten de sus tradiciones culturales. Los poderes económicos contribuyen, sin reparos mayores ni un ápice de mala conciencia, a degradar los niveles de tutela social que los legisladores de los países descolonizados — antaño orgullosos de esos rasgos de modernidad - habían incorporado sus ordenamientos jurídicos.

La mundialización deja fuera de juego el contenido esencial o núcleo invulnerable de la libertad sindical. La facilidad de la libre circulación de capitales choca con la imposibilidad de la movilización geográfica de los agentes sindicales y con el ejercicio de sus libertades fuera del territorio de los Estados soberanos de origen. Dificultades que se aprovechan para erosionar, aún más, la intervención sindical negociadora. El sindicato se ve reducido a funciones - menores o secundarias - que devalúan su protagonismo para fijar las cláusulas colectivas — de grueso calibreque acusaban la sustancia del cambio y la mejora de las condiciones de trabajo amparadas en la eficacia general de lo negociado. La intervención del poder sindical se empobrece en los frentes que, hurtados a la negociación colectiva, eran de ocupación indispensable para el juego del principio de irregresividad y la obtención de las ventajas a que su aplicación daba lugar. Ello afecta, no menos, a la suerte de la conmutatividad que, agredida por los poderes empresariales de organización y dirección, pierden las relaciones contractuales de trabajo.

La fertilidad tecnológica de la intercomunicación -que la mundialización acelera- estimula la aparición de novedosos procesos productivos. En la era de exaltación de la productividad, los empleadores 
-resueltos a violar los derechos constitucionales de los trabajadores e insensibles al fenómeno de la fatiga industrial y sus secuelas- aventajaban a unos sindicatos externos a las unidades productivas, sin la formación y el conocimiento requeridos para contrarrestar esos desmanes. La ventaja se eleva a la segunda potencia cuando el poder empresarial se entrega, en cuerpo y alma, a impermeabilizar los secretos tecnológicos de la era mundializadora. Las situaciones abusivas, que surgen entonces, no sólo se sustraen al control, sino también a la comprensión conceptual de los agentes sociales legitimados para su denuncia y eliminación. La mundialización castiga al sindicato con una plaga de calamidades que incluye la dificultad de disección de peculiaridades económicas y/o tecnológicas que no se consigue asimilar. Los activos de la democracia industrial -hipotecada en estos términos- se devalúan y/o disipan, sufriendo un retroceso y facilitando la desaparición o el adelgazamiento de las cargas — gradualmente simbólicas- que pretendían convertir la libertad de empresa en el derechofunción que nunca llegó a ser.

La mundialización vuelve - como en los albores de las luchas sociales - a contractualizar las condiciones primordiales de la relación individual de trabajo, restaurando los inconvenientes del rescate - que beneficia de nuevo al empleador- del poder de dominación sobre su régimen y de la decadencia de la autonomía de la voluntad del trabajador por cuenta ajena. Su desamparo explica que, cuando entra en el palenque del rito de la contratación individual, se sienta prematuramente desmoralizado y vencido. De ahí, sólo hay un paso a la quiebra de los mínimos de solidaridad, a la dispersión de los fragmentos residuales de la conciencia de clase y a la confiscación de la dignidad indispensable para resistir. La decepción y los recelos que suscita el imperio de la contratación individual, son las contrafiguras de la adhesión despertada por las adquisiciones colectivas que, gracias a la eficacia general de los convenios, aumentaban el prestigio de los sindicatos. Los trabajadores advienen a una situación de conflicto impropio, al desvincularse — como resulta de la estrategia mundializadora- de los intereses de categoría que impregnaban aquellos estados de conciencia. El tratamiento estrictamente individual — purgado de aspiraciones solidarias - de sus intereses profesionales, les opone al frente que forman un protagonista común -el empleador contractualmente dominante - y el resto de los integrantes de la categoría. Cada autonomía individual es la ciudadela de un adversario que reacciona y obliga a reaccionar en pie de guerra.

La mundialización devalúa el Derecho Social a través de varios factores de degradación. A saber, el ejercicio irrestricto de unas liber- 
tades de establecimiento y circulación de capitales que incumplen sus funciones sociales, la desaparición o traslación a otros pagos de las bases físicas de los procesos productivos, la irrupción de tecnologías inaccesibles a la supervisión sindical, el demérito de la negociación colectiva y el engrandecimiento - desproporcionado y lesivo- de la contratación individual. Sin olvidar la complicidad de las instancias políticas - que contribuyen a erigir zonas de tributación debilitada y obstan a la sobrevivencia de ciertas unidades productivas- y la beligerancia con que, saboteando la rehabilitación del Derecho Social, los poderes económicos toman partido en las operaciones de su voladura controlada.

\section{Recivilización falsa del Derecho Social}

Una perspectiva pesimista contemplaría la mundialización como una carrera de gran velocidad, en la que participan cuantos se han concertado para destruir, sin dejar rastro de supervivencia, las adquisiciones que el Derecho Social quiso salvar del naufragio causado por la crisis económica y sus estados de enrarecimiento. Esta voracidad - ungida con la razón falaz de que sólo la regeneración económica repondrá unas adquisiciones sociales que hoy sufren la más indeseable de las suertes- defiende, alardeando de suficiencia técnica, las pautas de neoliberalización absoluta que, sin ocultaciones ni sonrojos, resucitan la — tan inquietante como falsa - tesis de la recivilización del Derecho Social.

La civilización del Derecho Social formó parte de un fenómeno mundializador que apreciaba, como constantes empíricas, los datos de la frecuencia, la habitualidad y la homogeneidad del reclutamiento contractual de los trabajadores dependientes. Su tarea se enderezaba a enriquecer el régimen de las relaciones individuales de trabajo con las aportaciones llegadas de la Teoría General del Derecho, de la Parte General del Derecho Civil y del Derecho Común de las obligaciones, amén de los auxilios del Derecho Constitucional y el Derecho Administrativo. Cae de su peso que esas contribuciones ayudaban a erigir un edificio interdisciplinar de calidad y consistencia óptimas.

La inauténtica recivilización del Derecho Social deviene el instrumento que, como insustituible panacea, esgrimen los adictos a la mundialización. Remedando el estilo caduco de la publicidad filomarxista, abogan por un régimen de relaciones de trabajo desregulado hasta el punto de que no es fácil diferenciar su desaparición de lo poco que, tras esa depredación, queda de aquéllas. Propugnan la vuelta al tratamiento - escuálido 
y escueto- del arrendamiento de servicios demoliberal y les encandila la idea de liquidar los restos de las adquisiciones sociales que, tras la fulminación del principio de irregresividad, permanecen enhiestas.

Cualquier Estado soberano puede aceptar — por motivos no siempre confesables - unos u otros de los avances de la mundialización que repercuten negativamente, como hecho consumado, en las relaciones de trabajo. Dicha actitud sepulta las más dilectas ambiciones de la Política Social, doblegándose ante los poderes de hecho que - escudados en las recetas del pensamiento débil- pretenden abolir aquélla y reemplazarla por el juego de las fuerzas que convergen en un mercado sumiso y dominable.

\section{Racionalización moral de la vida económica}

Los aspectos de la mundialización requieren operaciones revisoras que tienden a racionalizarla. La democracia consumó una racionalización moral de la vida política que, en la era de la contestación, fue imitada por los moradores de otros ámbitos y provocó profundos cambios. La universidad accedió a la reconversión democrática que exigía la desaparición de la autocracia profesoral, del monopolio de las verdades humanísticas y científicas, y de la negativa a asimilar las aportaciones más dignas de ingresar en el mundo del pensamiento. La familia se sometió a las mudanzas dictadas por un decisionismo sociológico que, además de complicar su estructura, invirtió las relaciones de jerarquía y afección que de antiguo le caracterizaban y cuya excelencia no deja de reivindicarse. La sociedad mostró el exuberante pluralismo que provenía de superar la simplicidad del dualismo inicial — poseedores de bienes frente a desheredados - y se organizó en grupos y frentes que, como referente de su evolución, agravaron la nota de conflictividad. Las confesiones religiosas reclamaron la introducción de estilos democráticos en las acciones de dirección y de gobierno que, hasta entonces, abundaban en los hábitos del autoritarismo y de la obediencia inexorable.

Estos ensayos -inspirados en los propósitos de una Moral participativa- son difíciles de trasladar, hoy día, a la racionalización moral de la vida económica y de atenuar la dureza de las innovaciones mundializadoras. No pocos obstáculos lo impiden. La división entre moralistas y juristas —que nunca alcanzaron su punto ideal de convergenciaconstituye el primer impedimento. Los movimientos correctores de la mundialización abusiva tropiezan con la prevención férrea de quienes la mantienen y con la dificultad técnica de coordinar el pensamiento y 
la acción de cuantos coinciden en su necesidad. Las comunidades —más o menos conocidas o ignoradas - a que la mundialización se ha extendido, no cuentan con aparatos de promoción y propaganda que les enardezcan lo bastante para alzarse contra sus demasías.

No es fácil ni sincero formular, en estas condiciones, un augurio que garantice de inmediato el recobro del paraíso perdido de las adquisiciones sociales, pero tampoco es improbable que, a la vuelta de la esquina de los episodios históricos, aguarde, oculta todavía, la iniciativa - iprovidencial o milagrosa? - que permita ir en busca del tiempo perdido y situar a la persona humana en los espacios habitables de una ciudad terrestre donde ame, sirva, conviva y edifique.

Los teólogos juristas del siglo XVI - conscientes de las dimensiones del mundo de su tiempo y del peligro explicito en la teoría del derecho divino de los reyes- reflexionaron sobre estas circunstancias para construir un cuerpo de doctrina cuya combatividad ha pasado a la Historia. Se definieron - con contundencia y riqueza de argumentosen pro de la atribución del poder político al pueblo en el que, por imperativo del orden natural, residía la soberanía.

Siguiendo este modelo, hoy no es descabellado ni ocioso aspirar a que - ante el torrente de datos que procura la presencia, en los más remotos rincones del mundo, de tantos cuyo pensamiento y acción defienden la esperanza de una humanidad más humana y una vida más justa - se levante, a cargo de sus aportaciones y experiencias, el novísimo Derecho Universal de las relaciones de trabajo. Un orden natural que haga inventario - exhaustivo y honesto - de los cambios de las realidades sociales, que - serena y sabiamente- denuncie el deterioro causado por los excesos de la mundialización, y que, con los valores de su disposición cooperativa, renueve los principios de la dignidad y el respeto que merece y, ello no obstante, va perdiendo una Política Social herida de muerte por las agresiones del neoliberalismo salvaje. 